\title{
APPLYING EFFECTIVE STRATEGIES TO REDUCE ROAD CONGESTIONS IN INDIA (DELHI)
}

\author{
Kandukuru Jagan Mohan Reddy \\ Research Scholar (Ph.D), Department of Civil Engineering, \\ Noida International University (NIU), Greater Noida, India \\ Dr. Paritosh Srivastava \\ Professor, Head-Department of Civil Engineering, \\ Noida International University (NIU), Greater Noida, India
}

\begin{abstract}
The study aims to provide evidential measures to showcase the current traffic conditions of Delhi, India. The study provides strategic measures that enable the management of traffic congestion so as to develop the economic and environmental conditions. The study has been conducted based on situational analysis providing effective strategies that addresses the congestion solutions. Moreover the solutions that have been devised has been aligned to that of its affectivity in application. Conclusions have been driven to recommend future solution to the traffic congestion problem.
\end{abstract}

Keywords: Traffic Congestion, Situational Analysis, Management Strategies.

Cite this Article: Kandukuru Jagan Mohan Reddy and Dr. Paritosh Srivastava, Applying Effective Strategies to Reduce Road Congestions in India (Delhi). International Journal of Civil Engineering and Technology, 11(3), 2020, pp. 13-23. https://iaeme.com/Home/issue/IJCIET?Volume=11\&Issue=3

\section{INTRODUCTION}

Traffic congestion is one of the most common problems that are faced by individuals all over the world, especially in developing countries. The increase in the population of the countries has led to a rapid urbanization due to itching congestion has been observed. The study describes an overall situational analysis of the current condition of India's traffic condition and management systems. The study also claims to recommend appropriate strategies to overcome the issues related to congestion in traffic. The government of India needs to establish several management strategies so that congestion is reduced effectively in Delhi. 


\subsection{Background of the Study}

The study projects an overview of the current traffic conditions of India based on the situational analysis of Delhi, as the main target city. According to the performance measures of the current traffic management systems, it has been observed that, due to ineffective strategies, the management teams are unable to optimize traffic, especially during peak hours. This led the city to face pollution along with delay issues. Moreover, excessive exhaust from the vehicular transport of this region entangled with the increase in temperature of the city that led to global warming. The study illustrates various strategic measures that address the traffic congestion system of India and provides relevant and efficient measures to overcome the currently faced issues (Refer to Appendix 1).

\subsection{Rationale}

Insufficient road capacity has been identified as one of the major reasons due to which the city of Delhi faces congestion issues. This, in turn, consumes a huge amount of time to reach the destination from a particular source for the citizens. Similarly, being a metropolitan city, Delhi faces this issue due to the high amount of road transport operations that occur on a daily basis. Moreover, rapid urbanization has also affected the congestion issue highly as it occupied an ample amount of spaces from the edges of the roads (pib.gov.in, 2020). Effective management strategies are necessary to be developed so that congestion would be managed effectively. The study sheds light on proving solutions to road traffic issues to mitigate them and provide smooth passage of vehicular transport.

\subsection{Aim}

The study aims at establishing development strategies that would help the traffic management team of India to reduce congestion issues.

\subsection{Objectives}

- To understand the prime issues of road congestion in metropolitan cities

- To evaluate various strategic approaches that addresses road congestion

- To recommend development methods that would benefit from managing traffic congestions

\subsection{Research Questions}

1. What are the various issues faced by individuals on having traffic congestions?

2. What strategies are applicable to address traffic issues?

3. What measures could help in the management of traffic in the future? 


\section{LITERATURE REVIEW}

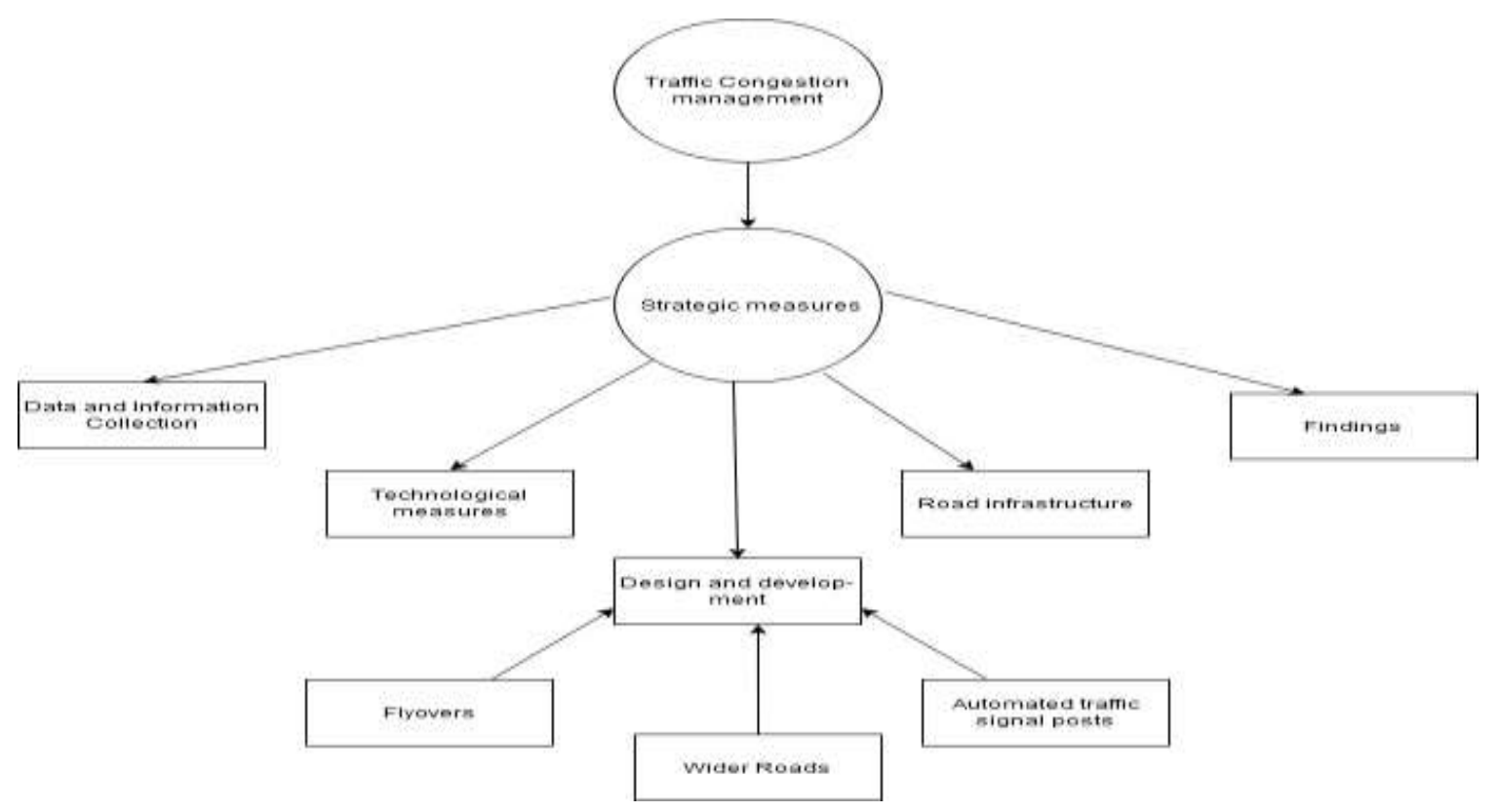

Figure 1 Conceptual Framework

(Source: Created by author)

\subsection{Impact of Traffic Congestions in India}

Road congestion leads to delay in transport as well as incurs diverse effects on the mentality of the travelling individuals. In other words, Lal et al. (2016) opined that especially during peak hours, it has been observed that traffic conditions become worse than lead to individuals using road transport to incur a delay in reaching their destination. The main reason for this is an increase in waiting time in signal queues. Moreover, Garg and Kaushal (2017) argued that congestion in a particular area for a long duration affects its surrounding environment with a huge amount of pollution released by the exhaust of the vehicles. This, in turn, pollutes the environment as well as leads to increased fuel consumption.

\subsection{The Necessity for Reducing Congestions}

Reduction of road congestion is one of the major issues that developing countries put their efforts to resolve. This, in turn, would provide the citizens of their state to improve their lifestyle and health. As per Zhao et al. (2017), in urban areas, there has been a huge amount of vehicle exhaust that is released into the atmosphere increasing global warming. This leads to an increase in the temperature of a particular region. On the other hand, Nellore and Hancke (2016) exclaimed that management of traffic congestions would eventually reduce the chances of waiting time in the traffic queues and thereby reduce the chances of environmental pollution. Moreover, reducing road congestion effectively decreases the delay time of the individuals to reach their destination from a particular source. As stated by Marchon and Pereira (2017), often individuals have been observed to be engaged in road rages due to ineffective decision making of the drivers. The reduction of congestion would enable drivers to communicate through their driving skills and make decisions regarding route selection, thereby, reduce the frustration of the drivers.

- Reduction of environmental pollution

- Quick and efficient transport from source to destination 
- Improvement of the lifestyle of individuals

- Reduction of chances of accident occurrences

- Reduce the chances of road rage

\subsection{Role of Governing Bodies to Control Congestions}

Taking into account the case of emergency vehicles, due to ineffective management of road traffic, the ambulances are unable to pass by and may lead to the death of emergency patients. Therefore, the governing bodies are suggested to apply for various management techniques that would separately develop provisions for ambulances to reach hospitals within a specific time eliminating the chances of congestion. As per Cardwell et al. (2016), in addition to this, government bodies are responsible to devise techniques and approaches that would effectively address the congestion problem to the individuals. For instance, developing foot-over bridges often help individuals to cross the roads without affecting traffic mobility. The government of India, in this case, puts efforts to devise traffic rules and regulations to the citizens. As concluded by Hastenreiter et al. (2018), foot over bridges solution not only benefits the reduction of traffic jams but also incur safety issues to the individuals while crossing roads. In addition to this, the government bodies are responsible to gather funding from various sources that would support the development process.

\subsection{Strategic Approach to Traffic Management}

Road infrastructure, in this case, plays an important role that determines the various routes that connect a particular destination. As stated by Coşar and Demir (2016), in developing countries, a well-established road infrastructure provides the traffic management team to benefit from separating busses and cars in different routes such that no congestion occurs in the junctions. In order to perform this, the governing bodies are recommended to apply for strategic planning before constructing roads, especially near the junction areas. For instance, increasing the volume of the roads based on its width would enable more vehicles to pass through at a single time thereby reducing the occurrence of congestion. On the other hand, decreasing the waiting time at each signal post needs to be managed efficiently such that vehicles need to be kept saying for a long time in the queue. However, Carpio (2020) contradicted that the traffic management bodies are suggested to establish rules that would directly address the road transport vehicles to shut down their engine while washing in a queue. This would eventually reduce the exhaust to the atmosphere thereby reducing pollution.

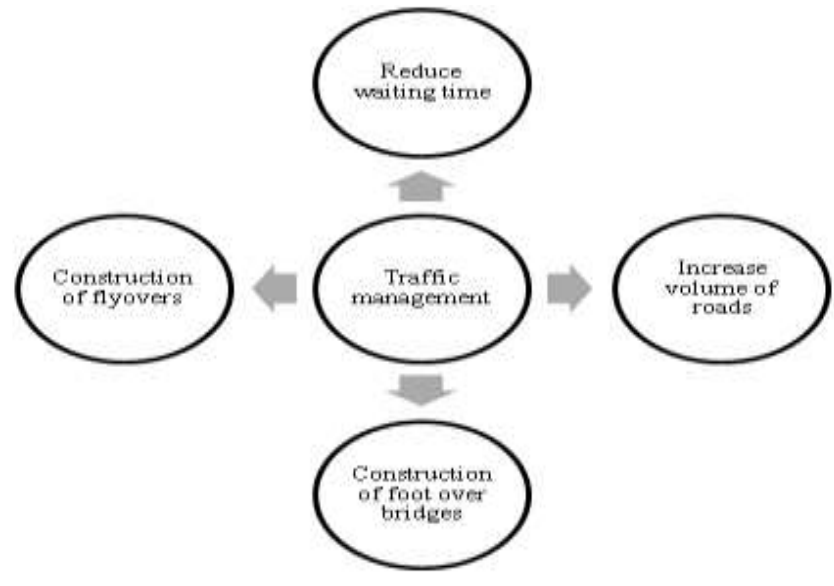

Figure 2 Traffic management strategies

(Source: Influenced by Beevers et al. 2016) 
Considering the concept of zebra crossings, individuals often use this method of road crossing that eventually increases the average waiting-time of the traffic signal post. As opined by Rego and Semente (2018), waiting time is identified as one of the major reasons for traffic congestion. The replacement of zebra crossing concepts to that of foot-over bridges would eventually increase efficiency in managing traffic as well as benefit individuals to derive road safety measures. Concluding from the benefits of flyover construction, it could be stated that, flyovers prevent congestion and eliminate the concept of the waiting queue in a signal post. Generally, Graham (2018) stated that flyovers are constructed focusing on the transportation of smaller vehicles such as cars and SUVs whereas roads are meant for buses. The application of this strategy enables the traffic governors to manage and evaluate congestion issues and thereby providing the individuals with a safer environment.

\subsection{Introducing Traffic Controlling Systems}

Implementing technological measures to reduce traffic conditions would effectively benefit the traffic management authorities to gain the benefit of devising solutions to congestion issues. In other words, Radio Frequency Identification (RFID) is a technology that has been developed by experts to handle traffic conditions through monitoring and visualizing. According to Ali and Haseeb (2019), RFID provides a smart way of managing traffic signals that would establish a waiting time depending upon the number of vehicles travelling through that route. This system provides an algorithmic approach to the traffic management system through the integration of microcontroller and wireless sensors. Based on the current traffic signal mechanism, the waiting time is established at a random due to which unnecessary waiting is incurred by the vehicles.

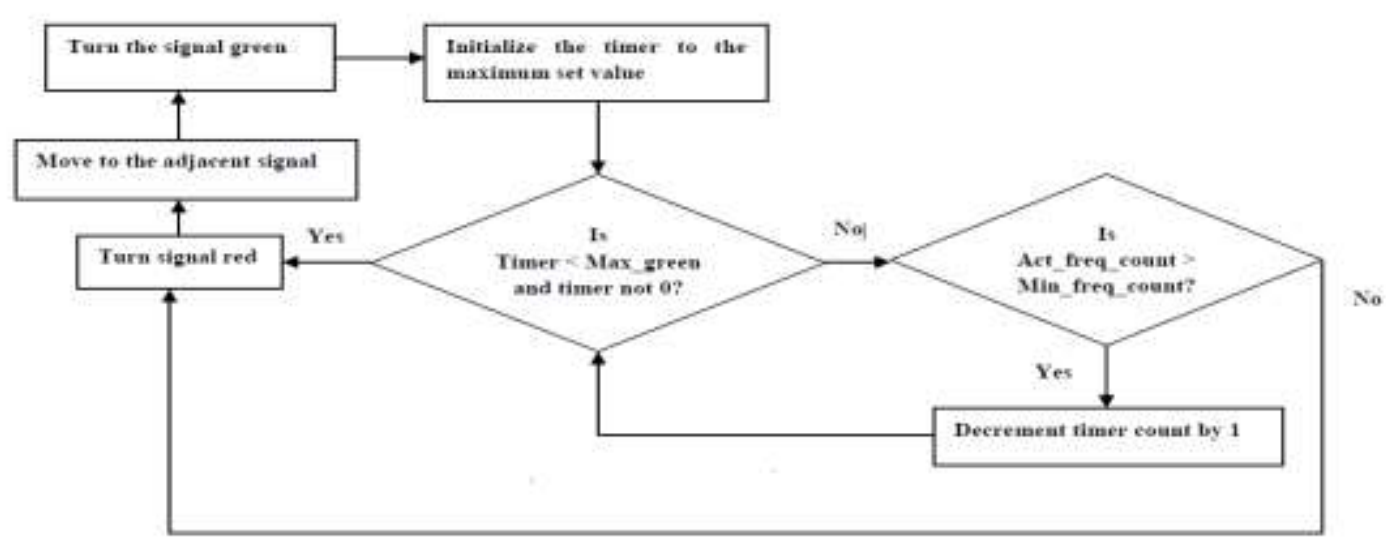

Figure 3 System Architecture of RFID

(Source: Influenced by Ali and Haseeb, 2019)

\subsection{Literature Gap}

The study fails to provide evidence to indicate the effectiveness of the various strategic measures that have been addressed. Moreover, the alignment of these strategies within the traffic management system may not be feasible enough due to insufficient budgetary requirements of its implementation. However, the inclusions from the literature would provide opportunities to select the appropriate type of methodology that would be supplied to implement the strategies. 


\section{METHODOLOGY}

\subsection{Research Philosophy}

As the research focuses on developing effective strategies to maintain traffic conditions and reduction of congestion, there needs to be consideration of real-life events rather than imaginative ones. Based on this applicability, the positivist theory would be chosen as the primary philosophy for the research to proceed. As per Siponen and Tsohou (2018), the application of this approach would enable the derivation of conclusion from the application of various possible methods that would address the issues of congestion. In this way, the government of India would be able to focus on the development of the mentioned strategic measures from a feasible perspective. Interpretive has not been applied in this research as it would not provide provisions to consider real-life future development aspects rather concentrate applicable concepts.

\subsection{Research Approach}

Developing countries are often observed to be concentrating on situational analysis rather than optimistic ways of performing development. This enables the governing bodies to consider the past effects and events that occurred due to coughing. It incurred the applicability of the new development procedures. Considering the case of road traffic congestion, the government of India would be acknowledged with the ideas of developing traffic management strategies from past events and issues. Hence, it could be stated that there would be a validated reason for choosing the deductive approach instead of inductive approach. The benefits of the deductive approach, in this case, would benefit in considering conclusions from the events that have already occurred such that mitigation strategies would be eventually applied.

\subsection{Research Design}

The application of the deductive approach indicates explicit background research about the issue such that appropriate mitigation techniques could be applied. As opined by Koyuncu and Kılıç (2019), in correspondence to this, the flexibility of the research would be balanced with the collaboration of exploratory design. In other words, the exploratory method of research design provides an effective balance to the deductive approach to attain sustainability to resolve the issue faced. Relating this measure to that of controlling congestion, there have been evidential reports that have been considered as the base of the study to eliminate congestion in Delhi. Therefore relevant information about mitigating congestion issues would be collected from samples through interview questions and other respondent approaches. In this way, the perspectives of every sampled individual would be taken under consideration thereby projecting distinct solutions.

\subsection{Data Collection}

Data collection methods include primary and secondary data that applies to the problem to be solved using direct and indirect methods. Based on the issues of congestion, the appropriate method that would be applied in this case is the primary data collection. As per Salam et al. (2016), the characteristics of this method, real-time data would be collected. In other words, the traffic congestion problem has always been a major concern on a day to day basis. Hence, the application of secondary data collection would not be preferable as it symbolizes past events rather than concentrating on predent events/. Through primary data collection, it would be possible to deduce the current situational analysis of Delhi's traffic congestion problem and thereby establish solutions to mitigate these problems. 


\subsection{Data Processing and Analysis}

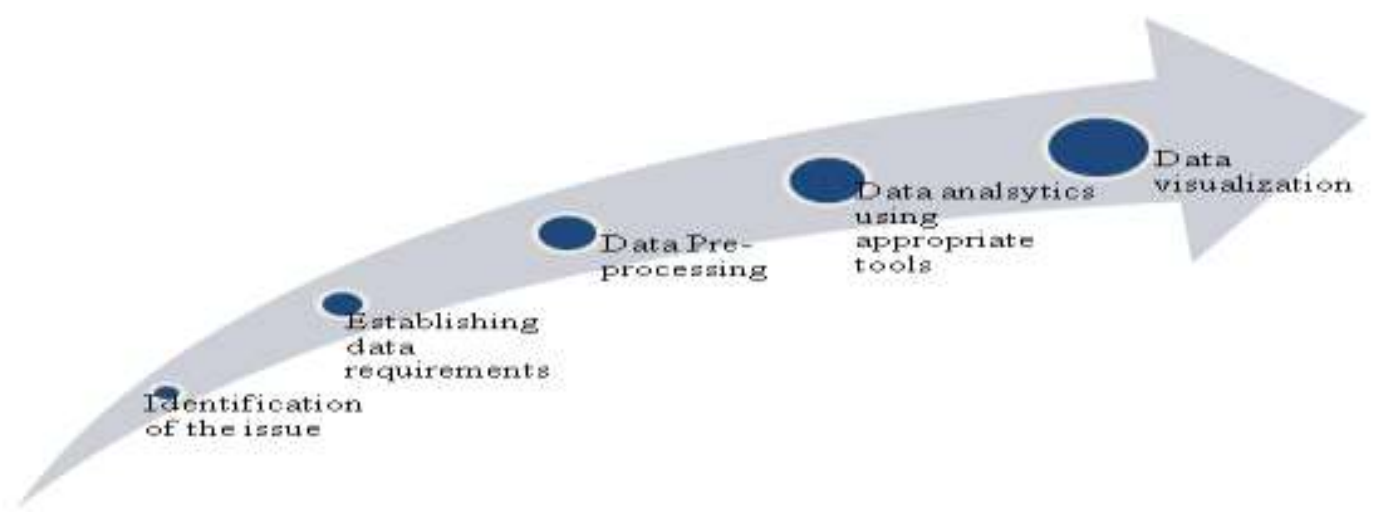

Figure 4 Data analysis process

(Source: Influenced by Zhao et al. 2017)

Performing data analysis requires the analyst to incur tools that support the processing of data and so on. This indicates a sequential approach to gain relevant information from the collected data. As per Blumenberg and Barros (2018), the data collection method applies for primary data, therefore, a chance of acquiring redundant data is possible. In order to eliminate redundancy and gather relevant information, there needs to be a database within which the collected data would reside. In addition to this, Sawall et al. (2019) opined that a huge amount of data requires computing on a specialized platform. This indicates a need for big data processing software to initiate the analysis process. Through this analysis, the information regarding congestion in traffic would be gained and significantly, solutions to the problems would be divided considering all aspects of development.

\section{FINDINGS}

\subsection{Construction of Flyovers to differentiate Vehicle Capacity and Rarefy Roads}

According to the observed evidence, of the current situation of India's traffic conditions, there is an indeed need for flyovers construction to facilitate citizens to avail effective road transport. In other words, Graham (2018) stated that, flyovers provide a differentiated pathway as an alternative route connecting two specified locations. The benefits of having this measure enable the road users to save their time when travelling long distances. On the other hand, Wang et al. (2018) stated that public transports such as buses would gain less congested roads as small cars and SUVs would be using flyovers for their transport. A $2.85 \mathrm{~km}$ signalfree RTR Flyover has been constructed that connects IGI airport and Noida costing approximately Rs. 205 crore on the outer ring road (economictimes.indiatimes.com, 2020). Additionally, there has been an initiative by the current government of India about establishing 70 flyovers during the next 15 years of development.

\subsection{Construction of Wider Roads to Manage more Vehicles at a Time}

Based on the current situation of Delhi's traffic, there has been a huge number of vehicular transports observed during recent years. This led the city to face immense traffic jams. Moreover, Cronkite-Ratcliff et al. (2016) stated that during the morning and evening session, this congestion has been observed to be increasing at a very high rate. Through the appropriate application of road construction mechanisms it could be estimated that even after having more transport, there would be fewer occurrences of traffic jams and congestion. 
Wider roads provide the traffic governing bodies to facility to control more vehicles at a time when compared to narrow roads.

\begin{tabular}{|c|c|c|}
\hline Year & Award (kms) & Construction (kms) \\
\hline $2014-15$ & 7972 & 4410 \\
\hline $2015-16$ & 10098 & 6061 \\
\hline $2016-17$ & 15948 & 8231 \\
\hline $2017-18$ & 17055 & 9829 \\
\hline
\end{tabular}

Figure 5 Average road expansion

(Source: pib.gov.in, 2020)

\subsection{Implementation of Traffic Management Systems}

As per the functional abilities of the proposed traffic management system, these smart devices are capable of streaming the congestion level at a particular region and provide assistance to minimize the congestion rate. In other words, De Souza et al. (2017) stated that, the signal posts are integrated with this system so as to detect the number of traffic movements of a place. In this way, the device performs its functionality by projecting an estimated waiting time to the vehicles. As per Gao et al. (2017), compared to the general traffic signal queue, the waiting time has an abrupt value irrespective of the traffic condition for that place. Therefore, through the implementation of this system, there would be effective management of vehicle congestion through a complete analysis of the present road traffic condition. Delhi Police have been planning to implement an Intelligent Traffic Management System (ITMS) that would cost them Rs. 1000 Crore which would include a 3D radar-based red light violation detection camera across 24 junctions of the city (indiatoday.in, 2020).

\section{5: CONCLUSION}

\subsection{Conclusion}

Traffic congestion is the most common occurrence that is faced by citizens of India. The daily transport facilities that are adopted by the residents of Delhi are increasing at a high rate. This has been identified as one of the reasons due to which congestion occurs due to an increase in vehicular transport. The road network of India concentrates on a single way transport from a source to a destination. This implies as evidence that a particular road is used by all the transporting individuals instead of alternative ones. Considering the impacts of traffic congestion, individuals have been observed to be facing several health issues as well as affecting the quality of life in a negative way. Traffic congestion also possesses an adverse effect on the economy as well as the surrounding environment. Therefore, it could be concluded that reduction of congestion in the environment of Delhi is an important issue that is to be mitigated by the government of India.

\subsection{Future Scope}

Development of congestion free roads not only initiates economic development but also derives the constraint of health and safety environment. Through the implementation of RFID system, the traffic signals would be integrated in such a way that it would be capable enough to identify the road congestion based on which the waiting time would be projected. For 
instance, road junctions, where fewer individuals are crossing the road, requires less waiting time to be incurred to the vehicles and vice versa. Hence, this technology needs to be incorporated in the areas where congestion is detected at maximum. The implementation of the RFID system would be complicated and would require the development team to gain a sufficient amount of findings but would benefit the nation to reduce congestion accordingly.

\subsection{Recommendations}

- The government of India is recommended to apply for sufficient finding such that there would be able to incorporate the implementation of the RFID system.

- There needs to be effective research on the road infrastructure of Delhi that would be required for redesigning such that roads could be made wider.

- The government of India needs to consider the sections of their city where congestion occur the most so that development could be carried out on prior to those locations.

- Non government organizations are to be involved in awareness programs that would acknowledge the drivers to shut down their engines while waiting in the signal queue to reduce environmental pollution.

\section{REFERENCES}

[1] Ali, A. and Haseeb, M., (2019). Radio frequency identification (RFID) technology as a strategic tool towards higher performance of supply chain operations in textile and apparel industry of Malaysia. Uncertain Supply Chain Management, 7(2), pp.215-226.

[2] Beevers, S.D., Carslaw, D.C., Dajnak, D., Stewart, G.B., Williams, M.L., Fussell, J.C. and Kelly, F.J., (2016). Traffic management strategies for emissions reduction: recent experience in London. Energy Emission Control Technol, 4(5), pp.27-39.

[3] Blumenberg, C. and Barros, A.J., (2018). Response rate differences between web and alternative data collection methods for public health research: a systematic review of the literature. International journal of public health, 63(6), pp.765-773.

[4] Cardwell, N., Cheng, Y., Gunn, C.S., Yeganeh, S.H. and Jacobson, V., (2016). BBR: Congestion-based congestion control. Quеие, 14(5), pp.20-53.

[5] Carpio, C.J., (2020). Capabilities of Traffic Enforcers in Implementing Traffic Rules and Regulations in Nueva Ecija. International Journal of Social Science and Economics Invention, 6(01), pp.115-123.

[6] Coşar, A.K. and Demir, B., (2016). Domestic road infrastructure and international trade: Evidence from Turkey. Journal of Development Economics, 118(3), pp.232-244.

[7] Cronkite-Ratcliff, B., Bergman, A., Vargaftik, S., Ravi, M., McKeown, N., Abraham, I. and Keslassy, I., (2016), August. Virtualized congestion control. In Proceedings of the 2016 ACM SIGCOMM Conference. 9(3).pp. 230-243.

[8] De Souza, A.M., Brennand, C.A., Yokoyama, R.S., Donato, E.A., Madeira, E.R. and Villas, L.A., (2017). Traffic management systems: A classification, review, challenges, and future perspectives. International Journal of Distributed Sensor Networks, 13(4), pp.15-22.

[9] Economictimes.indiatimes.com (2020). Delhi government built 23 flyovers in 4.5 years, says Arvind Kejriwal. Available at: https://economictimes.indiatimes.com/news/politicsand-nation/delhi-government-built-23-flyovers-in-4-5-years-says-arvind kejriwal/articleshow/ 70241983.cms?from=mdr [Accessed on 16.2.20] 
[10] Gao, J., Shen, Y., Liu, J., Ito, M. and Shiratori, N., (2017). Adaptive traffic signal control: Deep reinforcement learning algorithm with experience replay and target network. arXiv preprint arXiv:1705.02755.

[11] Garg, H. and Kaushal, E.G., (2017). Traffic Lights Control System for Indian Cities Using WSN and Fuzzy Control. Traffic, 4(07).pp.56-65.

[12] Graham, S., (2018). Elite avenues: Flyovers, freeways and the politics of urban mobility. City, 22(4), pp.527-550.

[13] Hastenreiter, I.N., Lopes, J.F.S., da Silva Camargo, R. and Forti, L.C., (2018). Avoiding traffic jams: Hitchhiking behavior as a strategy to reduce ant workers' traffic on the foraging trail. Behavioural processes, 157(4), pp.54-58.

[14] indiatoday.in (2020). Delhi police to launch several projects to improve traffic management. Available at: https://www.indiatoday.in/india/story/delhi-police-to-launchseveral-projects-to-improve-traffic-management-1427637-2019-01-10 [Accessed on 14.2.20]

[15] Koyuncu, I. and Kilıç, A.F., (2019). The use of exploratory and confirmatory factor analyses: A document analysis. Egitim ve Bilim, 44(198).pp.123-145.

[16] Lal, G., Divya, L.G., Nithin, K.J., Mathew, S. and Kuriakose, B., (2016). Sustainable traffic improvement for urban road intersections of developing countries: a case study of Ettumanoor, India. Procedia technology, 25(3), pp.115-121.

[17] Marchon, T. and Pereira, E., (2017). Road Rage across Age Groups. Psychological Researches, 60(1), pp.50-53.

[18] Nellore, K. and Hancke, G.P., (2016). A survey on urban traffic management system using wireless sensor networks. Sensors, 16(2), pp.157-180.

[19] pib.gov.in (2020). Ministry of Road Transport \& Highways. Available at: https://pib.gov.in/Pressreleaseshare.aspx?PRID=1557867 [Accessed on 13.2.20]

[20] Rego, R.C.B. and Semente, R.S., (2018). Presence sensor for people detection and reduction of pedestrian waiting time in traffic light. BTSym 2018 Proceedings., 1(1).pp.45-56.

[21] Salam, E., Hardi, S.M., Jaya, I. and Tarigan, J.T., (2016), December. Architecture for Epidemiological Data Collection System. In 1st Public Health International Conference.8(2).pp.12-22.

[22] Siponen, M. and Tsohou, A., (2018). Demystifying the influential IS legends of positivism. Journal of the Association for Information Systems, 19(7).pp.234-345

[23] Wang, C., Li, C., Qin, C., Wang, W. and Li, X., (2018). Maximizing spatial-temporal coverage in mobile crowd-sensing based on public transports with predictable trajectory. International Journal of Distributed Sensor Networks, 14(8), pp.15-51.

[24] Zhao, Y., Liu, P., Wang, Z., Zhang, L. and Hong, J., (2017). Fault and defect diagnosis of battery for electric vehicles based on big data analysis methods. Applied Energy, 207(2), pp.354-362.

[25] Zhao, Y., Saleh, R., Saliba, G., Presto, A.A., Gordon, T.D., Drozd, G.T., Goldstein, A.H., Donahue, N.M. and Robinson, A.L., (2017). Reducing secondary organic aerosol formation from gasoline vehicle exhaust. Proceedings of the National Academy of Sciences, 114(27), pp.6984-6989. 


\section{APPENDIX}

\section{Appendix 1: Average Congestion Rate based on Cities of India}

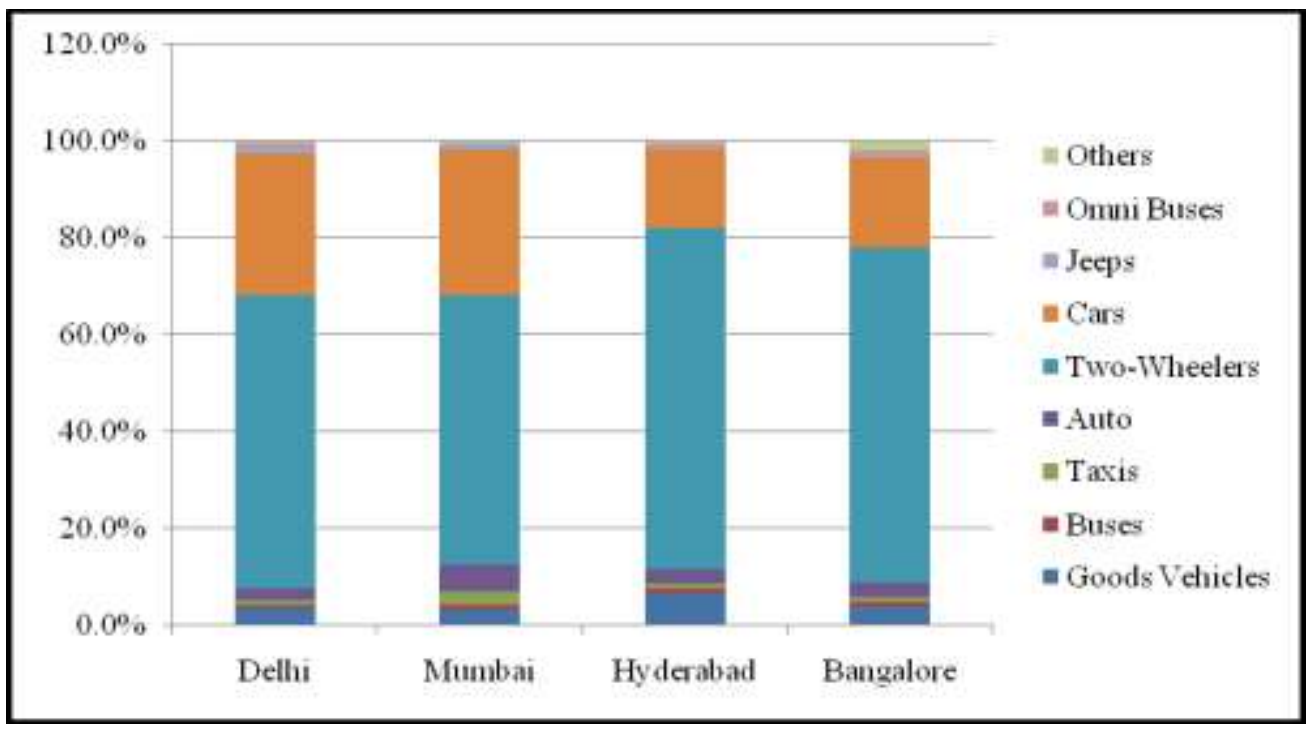

